\title{
The Role of Organizational and Individual Factors in Knowledge Management System Acceptance
}

\author{
Setiawan Assegaff* \\ Program Magister Sistem Informasi, STIKOM Dinamika Bangsa \\ Jl. Jend. Sudirman, Thehok, Jambi, 36138, Indonesia \\ *Corresponding author, e-mail: setiawanassegaff@stikom-db.ac.id
}

\begin{abstract}
The aim of this study is to investigates the how individual and organizational factors influence people behavior in using knowledge management. This research applied Technology Acceptance Model (TAM) as a basis theory; TAM was enriched with individual and organizational factors for this study. A survey approach was conducted for data collection. Three of institutions in Banking Sector at Indonesia were invited to join this study and 215 knowledge workers were participated for the survey. Data from survey were analyzed through Structural Equations Model (SEM) using PLS (Partial Least Square) V2. The conclusion specify that "individual elements" and "organizational elements" are the significantly affect people behavior in KMS acceptance factors that influence knowledge worker behavior in knowledge sharing. However this study not found relationship between individual and organization factors and "perceived ease of use" construct with people behavior in accept KMS.
\end{abstract}

Keywords: knowledge management system, technology acceptance, people behavior, individual factor, organizational factor

\section{Introduction}

Fast growing in Information Technology development has brought many benefits in support organization in manage their knowledge more effectively. Information Technology brings opportunity for the organization by providing various feature and ability in manage their knowledge [1]. The use of Information Technology to support Knowledge Management (KM) process is recognizing as Knowledge Management System (KMS). Todays, implementation of KMS has been considered a fundamental part of the KM projects [2]. It is believed that KMS give immense opportunities to break down barriers by making the information presented at every level and units in organization hence it will help to enhance organization becomes more effective [3]. There some example of Information Technology that could support Knowledge Management activities, such as a groupware, groupware is an application that develops to facilitate collaboration and sharing of knowledge among people in the community. Content Management Systems (CMS), this application could use to help people in creating the content and documents in the web system. Electronic Learning is developing to help the organization to conduct training and/or education using information technology. Video conference; this technology enables a member of one organization could conduct a virtual meeting with other company in remote location support by the internet [1].

Although Information Technology provides many values for KM in the organization, however, KM, in fact, is not all about Information Technology [4]. Previous research found the barriers in using KMS is not much about technology but it more about people and culture [4-6]. Research in KM and KMS has identified the main barriers in KM is not related with the Information Technology itself, however study in this area reveals that people/user behavior is became the main problem in $\mathrm{KM} / \mathrm{KMS}$ project success [7]. People are playing a vital role in KMS project; this is because people are the main actor in KM. People are actor that has the knowledge and they are also the actor who will contribute and receive the knowledge. IT is an enabler that would help people in contribute and receive the organizational knowledge. It is become critical for organization which develop KM to understand the reason why people use or not use the KMS. The interesting fact about using KMS is when people using the KMS (as tool/technology) he/she not only accepts the technology itself, but in the same time he/she also 
need to agrees to contribute or receive knowledge (known as Knowledge Sharing/KS). KS as the main activities in KM was influence by what she/he believe related with the KS. Cabrera and Cabrera [8] studies in KS explain people will do KS if they get maximal benefit from KS and provide minimal effort for KS. In accept KS people will consider what benefit and cost they have when conduct KS [9]. Some people conduct KS because of external driven and others because of internal driven, external motivation such as financial and nonfinancial reward and reciprocity is one of example from internal motivation [10].

In organizational context, people behavior is much influence by organization culture and policy [11]. When organization is able to create appropriate organization culture, people as member of organization will tend to have behavior according the organization culture [5]. In KM initiation, organization needs to pay attention and provide more effort to support the KM, by focus in develop an effective strategy [12] that brought a conductive environment with positive culture that will encourages people in doing KS [13]. With focus on people and organization factor, we argue organization could have better understanding in why people accept the KMS in KM initiation [14]. Better understanding in KMS acceptance is important for KM success; researches related in KMS acceptance argue that KMS acceptance became one of prominent agenda research in KMS area [2], [15-16]. In this research, we would like to contribute in making better understand why people are accepting and not accept the KMS. Our study focus to investigate factors influences people behavior in KMS acceptance both from individual and organizational factor. We applying TAM as a basis theory, we also consider both individual and organization factor to be investigated.

Our article outline describes as follow; the first section would describe introduction and the related study. The second section presents theoretical framework and hypotheses development for this study. The third section explains the research method. The last section we will provide data analysis, result, and discussion.

\section{Theory and Hypotheses Development}

\subsection{Theory Technology Acceptance Model (TAM)}

This study using the Theory Technology Acceptance Model (TAM) as the basic reference in resolving the issues raise in this study. TAM is one design that is constructed to evaluate as well as comprehend the variables that affect the approval of using computer technology which was initially introduced by Fred Davis in 1986. TAM is the outcome of the growth of the Theory of Reasoned Action (TRA), which initially established by Fishbein and also Ajzen on 1980. TAM aims to discuss as well as predict the function (acceptance) customers versus an information system. TAM gives an academic basis to establish the factors that influence the acceptance of the modern technology within a company. TAM clarifies the causal connection between confidence (the advantages of a system of information and also the simplicity of use) and actions, purposes, and also the actual use the individual/ user of an information system.

TAM model, in reality, is taken from the model TRA, it is the principles of reasoned action by using the hypothesis that the reactions and one's perception of things, it will certainly determine the mindset and also the behavior of the person. Responses, as well as understandings of users to Information Technology (IT), will certainly impact its perspective in the approval of these modern technologies. Among the elements that could affect it is the user's understanding of the effectiveness and also simplicity by the utilization of IT because an act that is reasonable in the connection to concerning modern technology, so the factor someone discover the benefits and also simplicity of use of IT making the activity/behavior of people such as standards in the approval of a technology.

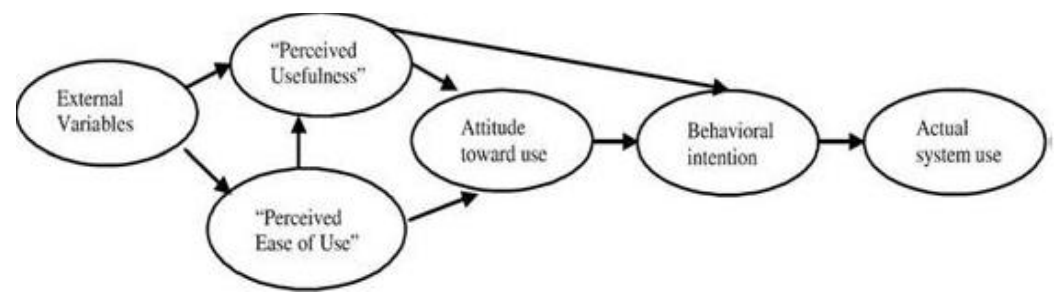

Figure 1. TAM model 
The studies which applied in this theory have been proven that this theory is able to explain and predict the behavior and the good intentions of a person's actual behavior. Researchers generally collaborate on this theory with other theories or add other relevant factors to be explored in connection with this theory can provide a better explanation of human behavior. In connection with the adoption of research in the field of KMS Acceptance then factor "Individual" and "Organizational" is regarded as a critical factor that must be considered to understand. Several studies which are evaluating the impact of factors "Individual" and "Organizational" in conjunction with the adoption of mobile KMS Acceptance [17-20].

\subsection{Development of Research Model and Hypotheses}

The following picture shows the relationship between variables in this study. The research model consists of six variables in Figure 2. There are three independent variables and three dependent variables. Four clusters of constructs such as external factors (consist of an individual and organizational factor), user belief (consist of perceived benefit and effort), social influences and KMS acceptance. The operational definition of each construct explains in Table 1. We conduct eight hypotheses; the hypotheses have been grouped under individual factors, organizational factors, and perceived benefit, perceived effort, social influences and KMS acceptance.

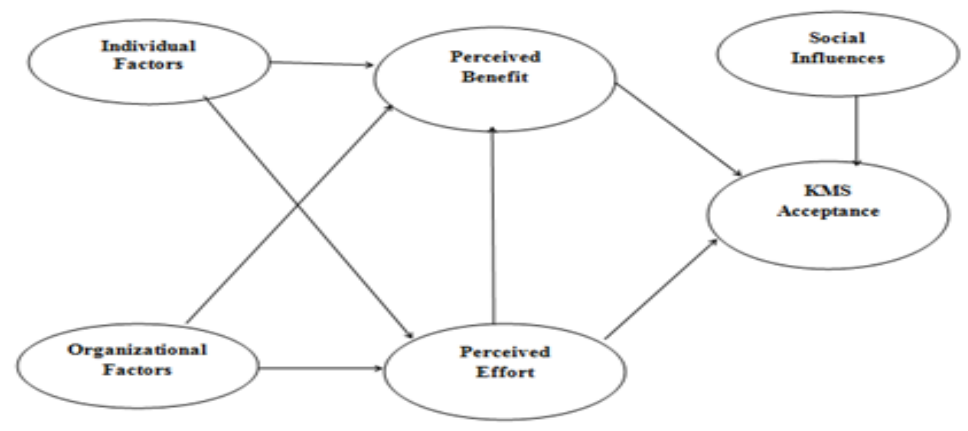

Figure 2. Research model

Table 1. Operational Definition of Variables

\begin{tabular}{|c|c|c|c|}
\hline Factor & Definition & Number of Indicators & References \\
\hline $\begin{array}{l}\text { Individual } \\
\text { factors }\end{array}$ & $\begin{array}{l}\text { Individual factors are the role of individual } \\
\text { difference (a role with regard to technology, } \\
\text { tenure in the workforce, prior experiences } \\
\text { and participation in training }\end{array}$ & $\begin{array}{l}\text { Five indicators for individual } \\
\text { factors have adapted from a } \\
\text { previous study. }\end{array}$ & [2], [21-28] \\
\hline $\begin{array}{l}\text { Organizatio } \\
\text { nal Factors }\end{array}$ & 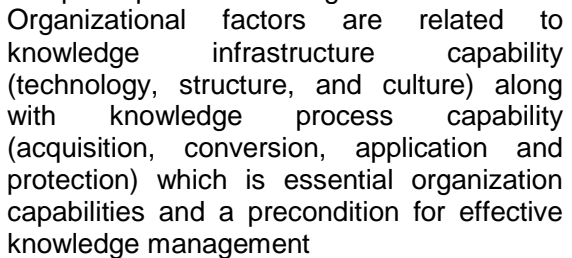 & $\begin{array}{l}\text { We adapted elephant } \\
\text { indicator from previous } \\
\text { studies to measure our } \\
\text { organizational factors. }\end{array}$ & $\begin{array}{l}{[2], \quad[15],[24-} \\
25],[29-34]\end{array}$ \\
\hline $\begin{array}{l}\text { Perceived } \\
\text { Benefit }\end{array}$ & $\begin{array}{l}\text { Perceived benefit is the degree to which an } \\
\text { individual finds using and contributing in } \\
\text { KMS give benefit and useful. }\end{array}$ & $\begin{array}{l}\text { Eight indicators have been } \\
\text { adapted for these studies }\end{array}$ & $\begin{array}{l}{[2], \quad[15], \quad[23-} \\
24], \quad[26-27], \\
[30-31], 34-40]\end{array}$ \\
\hline $\begin{array}{l}\text { Perceived } \\
\text { Effort }\end{array}$ & $\begin{array}{l}\text { Perceived benefit is the degree to which an } \\
\text { individual finds using and contributing in } \\
\text { KMS free of effort and or cost. }\end{array}$ & $\begin{array}{l}\text { We adapted eight indicators } \\
\text { to measure perceived effort in } \\
\text { this study }\end{array}$ & $\begin{array}{l}{[2], \quad[15], \quad[23-} \\
24], \quad[26-27], \\
{[30-31],[34-40]}\end{array}$ \\
\hline $\begin{array}{l}\text { Social } \\
\text { Influences }\end{array}$ & $\begin{array}{l}\text { Social Influences is an individual's } \\
\text { perception that most people who are notable } \\
\text { to the individual think he or she should or } \\
\text { should not use the KMS }\end{array}$ & $\begin{array}{l}\text { Three indicators have been } \\
\text { adapted for this study }\end{array}$ & {$[25,41]$.} \\
\hline $\begin{array}{l}\text { KMS } \\
\text { Acceptance }\end{array}$ & $\begin{array}{l}\text { KMS Acceptance is the decision to using or } \\
\text { using the KMS }\end{array}$ & $\begin{array}{l}\text { We adapted eight indicators } \\
\text { to measure KMS acceptance } \\
\text { construct in this study }\end{array}$ & $\begin{array}{l}{[2], \quad[15], \quad[23-} \\
24], \quad[26-27], \\
{[30-31],[34-40]}\end{array}$ \\
\hline
\end{tabular}




\subsection{Individual Factor}

Past studies [2], [21], [25], [28] specify that the end/individual/user characteristic 'different are decisive aspects in describing/forecasting the technology acceptance. Furthermore, Davis (1989) in technology acceptance model recommends that external variables such as individual variables will influences system acceptance by affecting perceived usefulness. External factors are substantiated to have a direct impact on PU. External factors may include system feature, training, document support consultations [24]. External factor provides "the bridge between the internal beliefs, attitude, and intention represented in TAM and the various individual different situation constrains and managerially controllable intervention impinging on behavior [24]. Furthermore, a study by Agarwal and Prasad (1999) found that individual different have influenced individual belief (in this context PB and PE) in technology acceptance. Our propose hypotheses for individual factors are:

$\mathrm{H} 1$ : Individual Factor will have a direct impact to Benefit of using KMS

H2: Individual Factor will have a direct impact to Effort of using KMS

\subsection{Organizational Factor}

Previous studies [2], [42] reveals that organizational aspects have an influences people in the acceptance of the technology. Relevant with that, Davis [24] suggests that in the technology acceptance model, the external factors such as individual factors will influences knowledge management system acceptance by impact to perceived usefulness factors. External factors are substantiated to have a direct impact on Perceived Usefulness. External factors could consist of system feature, training, document support consultations [24]. External factor provides "the bridge between the internal beliefs, attitude, and intention represented in TAM and the various individual different situation constrains and managerially controllable intervention impinging on behavior [24]. Our propose hypotheses for organizational factors are:

H3: Organizational Factors will have a direct impact to Effort of using KMS

$\mathrm{H} 4$ : Organizational Factors will have a direct impact to Benefit of using KMS

\subsection{Perceived Benefit}

Perceived Benefit construct is modified from Perceived Usefulness construct of TAM [24]. Perceived Usefulness (PU) is a fundamental determinant of user acceptance of an information system. PU defined as "degree to which person believes that using a particular system would enhance his or her job performance [23]. Relevant with another IT acceptance researchers in other area, studies in KMS acceptance survey also found that perceived usefulness is a "crucial factor" of someone purpose to take advantage of KMS [2], [15], [23-24], [26-27], [30-31], [34-40] In addition TAM postulates PU is assigned by PEOU as well as external variable. Our propose hypotheses for perceived benefit is:

H5: Benefit will have a direct impact to KMS Acceptance

\subsection{Perceived Effort}

Perceived Effort was modified from original Perceived Ease of Use in TAM [24]. In TAM PEOU is one of the fundamental determinants of user acceptance of information system [2], [15], [23-24], [26-27], [30-31], [34-40]. PEOU postulated to have a direct impact as well as indirect on behavioral intention trough PU. TAM posits PU are specified by PEOU and external variable. PEOU is postulate having a direct impact on PU. Our propose hypotheses for perceived effort are:

H6: Effort will have a direct impact on benefit of using KMS

H7: Effort will have a direct impact to KMS Acceptance

\subsection{Social Influences}

We refer to Fulk et al. 1990 for social influences model in this research. This concept argues that people behavior will influence with other people who are important to him/her/lf the important people suggest he/she to do so, he/she will perform the action. Previous research found social influences have a direct effect on individual intention to use [2], [25-26], [42-43]. Our propose hypotheses for social influences are:

H8: Social Influence will have a direct impact to Benefit of using KM 


\section{Research Methodology}

\subsection{Sample}

Indonesia banking institution was selected for the survey setting. We invited the banks which have implemented Knowledge Management System. Five hundred questionnaires were distributed to the employees of selected Bank. Data was collected from the middle of September 2015 to early November 2015. To increase the responses rate, a reminder message was sent out two weeks after and respondents who return the questionnaire were given a souvenir [44]. There were two hundred and twenty questionnaires was return, and two hundred and fifteen questionnaire was valid. The final sample size is 215 subjects, and the reply rate ranges from $10 \%$ to $43 \%$ with an average reply rate of $25 \%$.

The respondent comprised of $63 \%$ male and $37 \%$ female. $37 \%$ of respondent were in group 31 to $35,26 \%$ in 36 to $40,16 \%$ in 41 to 45 and $14 \%$ in group younger than $30.62 \%$ of the respondent were holding the staff position, $10 \%$ were assistant manager and manager and $10 \%$ were supervisors. $73 \%$ of the respondent holds a bachelor degree, $24 \%$ having a master degree, $2 \%$ associate degree and $1 \%$ having a high school degree. $47 \%$ having years experiences for 2 to $5,29 \%$ for 6 to 10 , and $13 \% 11$ to $15,1 \%$ for 16 to 20 and 20 or more, and $8 \%$ for less than 1 year. Distribution of respondent base by the organization was as following: $17 \%$ from Bank A, 49\% from Bank B and 34\% from Bank C. The description of profile respondent listed in Table 2.

Table 2. Respondent Profile

\begin{tabular}{|c|c|c|c|}
\hline Information & Categories & Number & Percent \\
\hline \multirow{3}{*}{ Gender } & Male & 135 & $63(\%)$ \\
\hline & Female & 80 & 37 (\%) \\
\hline & Bank A & 36 & $17(\%)$ \\
\hline \multirow[t]{4}{*}{ Organization } & Bank B & 105 & $49(\%)$ \\
\hline & Bank C & 74 & $34(\%)$ \\
\hline & $31-35$ & 79 & $37(\%)$ \\
\hline & $36-40$ & 62 & $26(\%)$ \\
\hline \multirow{5}{*}{ Age Group } & $41-45$ & 34 & $16(\%)$ \\
\hline & $45-50$ & 9 & $4(\%)$ \\
\hline & 51or older & 1 & $1(\%)$ \\
\hline & 30 or younger & 30 & $14(\%)$ \\
\hline & Assistant Manager & 21 & $10(\%)$ \\
\hline \multirow{4}{*}{ Rank of Position } & Manager & 22 & $10(\%)$ \\
\hline & Staff & 133 & $62(\%)$ \\
\hline & Supervisor & 39 & $18(\%)$ \\
\hline & High School & 1 & $1(\%)$ \\
\hline \multirow{5}{*}{ Education } & Associate Degree & 5 & $2(\%)$ \\
\hline & Bachelor Degree & 157 & $73(\%)$ \\
\hline & Master Degree & 51 & $24(\%)$ \\
\hline & Less than 1 years & 18 & $8(\%)$ \\
\hline & 2 until 5 years & 102 & $47(\%)$ \\
\hline \multirow{4}{*}{ Years of Experiences } & 6 until 10 years & 62 & $29(\%)$ \\
\hline & 11 until 15 years & 28 & $13(\%)$ \\
\hline & 16 until 20 years & 3 & $1(\%)$ \\
\hline & More than 20 years & 1 & $1 \%$ \\
\hline
\end{tabular}

\subsection{Technical Analysis}

This research applied PLS for data analysis using Smart PLS V2 software. There are two main stages in data analysis; the first stage is conducted an evaluation of "measurement model". The second stage is conducted the structural model evaluation. The aim of measurement model evaluation is to ensure that the research instrument developed in this study met the criteria that have been determined for quantitative study. The structural model evaluation is conduct to test the research hypotheses.

\section{Results and Discussion}

The stages of the validation of the instrument are through a series of statistical evaluation. This part intends to make sure that the research study tool established in this study 
satisfied the requirement that has actually been identified in a quantitative study. In quantitative research, the validity and reliability to a research instrument is a task that needs to conduct.

\subsection{Instrument Measurement}

This study conducts three approaches of pre-testing such as face validity, content validity, and pilot study [45-46]. Information related the step of pretest explain below. The first stage in instrument validation is face validation. The aim of this stage is to get the feedback from expert in term of questionnaire content and design. Two expert in this filed were invited to provide feedback. The inputs from expert are use in improving the design. Several modifications were made to the wording and scaling of certain question.

After conduct face validation, this study performs content validation. Content validation is conduct with reviewing all of items on the questionnaire to make sure whether the questionnaire cover the overall topic in this study [47]. This type of validation is often the most powerful validation in developing new questionnaire. We invite three of experts to conduct our content validity. The experts are experiences as consultant in knowledge management. They have more than ten years in implementing Knowledge management in many organizations at Indonesia. Content validity conducts by review the items for construct using a scale to evaluate all of items. There are some method that could apply in evaluate degree of agreement regarding the content relevant of an instrument have been proposed. For this study one approach that recommended for several decades is apply. This method involving having a team of experts indicates where each item on the scale is relevant to the construct, computing the percentage of items deemed to be relevant for each expert, and then taking the average of the percentages across experts [47]. Average of percentages across expert known as ACP (average congruency percentage); if ACP is 90 percent or higher would be consider acceptable [47]. We created a list of all that items in the questionnaire to validate and check by expert's team. The items were grouping in their variable. Expert was asked to rate each scale of item. We provide 4 point scale base on Davis (1992); 1=not relevant, 2=somewhat relevant, 3=quite relevant, 4=highly relevant. The result showed all items in the questionnaire have ACP higher than $90 \%$.

The next step is perform pilot study, by conduct pilot study it is could increase reliability of measures [48]. This research conduct a pilot study conducted by ten KM Consultant employees. The objective of the study was to ensure that the survey instrument is clear and concise, to ass's time require completing the questionnaire and that the measurement items reveal their intended meaning. The pilot participants were asked to read the cover letter, complete the survey, and provide feedback, as well as overall reaction to the survey based on their experiences. Feedback was used to make the necessary adjustment to improve the questionnaire

\subsection{Validity and Reliability Test}

This study perform construct validity for evaluate the validity of the instrument. The aim of these activities is to make sure the instrument meet the criteria. Construct validity of the measures was evaluated regards to convergent validity and discriminant validity. The convergent validity of the procedure is specified as the level to which a collection of items merge consistently to determine a specific concept. It can be determined by using the variable loadings, composite reliability (CR) and also average variance extracted (AVE) standards [49]. To develop that, we analyzed the items' variable loadings and cross loadings to recognize if there are issues pertaining to some items. The cutoff value of 0.5 , as recommended by [49], was used to assess the goodness of items' loadings. Result from Smart PLS indicated that all items were got acceptable not including items KA 5 (0.42), KA 6 (0.49), KA 8 (0.41) and SI3 $(0.2)$ have loading values less than 0.50 . Next these items were reduced from more evaluations just to increase their item reliability. Therefore, the composite reliability was verified as significant factors of convergent validity. The composite reliability relates to the level to which a set of items shows consistently the latent construct [49]. As shown in Table 4, the composite reliability has specified limit from 0.884 to 0.954 that more than the recommended value of 0.7 thus represent an enough convergent validity [50,51]. Furthermore, the average variance extracted (AVE) that relates to the average variance extracted among a set of items, was analyzed. Actually, AVE can be utilized to measure the variance captured by the indicators with the variance assignable to the measurement errors. As recommended by Barclay et al. (1995), 
values of AVE higher than 0.5 show that the set of items has an enough convergence in determining the concern construct [52].

According to the final outcome of PLS Algorithm, from six construct have AVE value less than 0.5. Effort has AVE value 0.43 while Organizational Factor has value 0.37 . In order to increase AVE value we drop the items which have lowest loading value in each construct one by one. From effort construct item E7 (0.51) is found to be the lowest loading value among others. After drop E7 item, we check again AVE value for effort construct. Because AVE value was still below 0.5 , than we dropped the others item in effort construct E8 (0.47). Last AVE to effort increase after drop items E7 and E8 became 0.53. Next, we do some procedure for organizational variables construct. First item OG7 (0.53) as the lowest loading value among others were identified, and we drop it. Because AVE value for organizational factors was still not acceptable, then we dropped other items, OG11 (0.58), OG6 (0.56), OG10 (0.59), OG9 (0.54), and OG8 (0.53). After we drop the items from the model, AVE value for organizational factors increase became 0.52, and it was acceptable. Then model was retested and found have acceptable measurement properties for every item in each construct. Table 3 shows final items for its constructs and all the items greatly loaded on its respective elements when compare to their loadings on other factors.

Table 3. Cross Loading Factors

\begin{tabular}{ccccccc}
\multicolumn{7}{c}{ Table 3. Cross Loading Factors } \\
\hline & Benefit & Effort & $\begin{array}{c}\text { Individual } \\
\text { Factor }\end{array}$ & $\begin{array}{c}\text { KMS } \\
\text { Accept }\end{array}$ & $\begin{array}{c}\text { Org } \\
\text { Factor }\end{array}$ & $\begin{array}{c}\text { Social } \\
\text { Influences }\end{array}$ \\
\hline PB1 & 0.6985 & 0.3147 & 0.3008 & 0.5184 & 0.205 & 0.2641 \\
PB2 & 0.8164 & 0.3166 & 0.3456 & 0.4774 & 0.1995 & 0.2204 \\
PB3 & 0.8276 & 0.2731 & 0.336 & 0.4199 & 0.215 & 0.2417 \\
PB4 & 0.7583 & 0.2599 & 0.3739 & 0.3748 & 0.2656 & 0.2318 \\
PB5 & 0.7842 & 0.297 & 0.2351 & 0.4367 & 0.2786 & 0.2336 \\
PB6 & 0.8238 & 0.2583 & 0.2322 & 0.3766 & 0.1617 & 0.2854 \\
PB7 & 0.8221 & 0.2178 & 0.2365 & 0.3807 & 0.0441 & 0.2553 \\
PB8 & 0.8093 & 0.1962 & 0.249 & 0.3789 & 0.0687 & 0.2658 \\
PE1 & 0.2614 & 0.7519 & 0.238 & 0.129 & 0.292 & 0.1712 \\
PE2 & 0.1994 & 0.7617 & 0.231 & 0.1483 & 0.2784 & 0.1822 \\
PE3 & 0.3577 & 0.8337 & 0.2945 & 0.2345 & 0.2738 & 0.1667 \\
PE4 & 0.0935 & 0.7188 & 0.2727 & 0.1067 & 0.2732 & 0.1879 \\
PE5 & 0.3361 & 0.7267 & 0.2896 & 0.2355 & 0.275 & 0.3184 \\
PE6 & 0.1805 & 0.5358 & 0.3049 & 0.3153 & 0.4526 & 0.0546 \\
IF1 & 0.2419 & 0.3376 & 0.8027 & 0.3028 & 0.3426 & 0.1898 \\
IF2 & 0.3101 & 0.3579 & 0.8653 & 0.334 & 0.3599 & 0.1879 \\
IF3 & 0.2593 & 0.3155 & 0.7435 & 0.2853 & 0.467 & 0.1827 \\
IF4 & 0.2849 & 0.2189 & 0.6212 & 0.3013 & 0.3861 & 0.1784 \\
IF5 & 0.283 & 0.1406 & 0.6106 & 0.2931 & 0.2326 & 0.117 \\
KA1 & 0.3877 & 0.2568 & 0.348 & 0.8445 & 0.2833 & 0.2266 \\
KA2 & 0.411 & 0.157 & 0.2776 & 0.8433 & 0.191 & 0.1646 \\
KA3 & 0.4838 & 0.2315 & 0.3629 & 0.8941 & 0.2466 & 0.165 \\
KA4 & 0.5444 & 0.211 & 0.3355 & 0.887 & 0.2084 & 0.1359 \\
KA7 & 0.3436 & 0.321 & 0.3392 & 0.5781 & 0.2894 & 0.1996 \\
OG1 & 0.1675 & 0.2264 & 0.3445 & 0.2195 & 0.7671 & 0.1211 \\
OG2 & 0.127 & 0.204 & 0.3355 & 0.1664 & 0.6894 & 0.1219 \\
OG3 & 0.1555 & 0.264 & 0.2861 & 0.2393 & 0.7305 & 0.0206 \\
OG4 & 0.1928 & 0.369 & 0.4526 & 0.2104 & 0.6691 & 0.129 \\
OG5 & 0.1866 & 0.414 & 0.3145 & 0.223 & 0.7353 & 0.0554 \\
SI1 & 0.3022 & 0.2474 & 0.2196 & 0.2028 & 0.127 & 0.9878 \\
SI2 & 0.3189 & 0.2424 & 0.244 & 0.2257 & 0.1149 & 0.9902 \\
\hline PB=Perceived Benefit & PE=Perceived Effort & IF=Individual Factors \\
KA=KMS Acceptance & OG=Organizational Factors & SI=Social Influences
\end{tabular}

As presented in Table 4 the AVE calculates of all the constructs get more than the minimum level, ranging from .62 to .97. The AVE is greater than .50 is thought appropriate, which indicates that "There are $50 \%$ or more variance of the indicators should be considered for" [53]. In summary, these results indicate that all the constructs in the model prove about high internal consistency. Next we will check the reliability of each construct. Reliability is the level to which "a specific method, used continuously to the similar item, which could generate the similar outcome each time" [50-51]. Reliability is assessed with both composite reliability and Cronbach's Alpha. A value of at minimum 0.70 was applied as the thresholds to show suffice 
reliability (Nunnally 1978). We can look on Table 4 that present the reliability of the constructs. Each one of the constructs had great reliability and scored well above 0.70 .

Table 4. Reliability Indicator

\begin{tabular}{cccc}
\hline & $\begin{array}{c}\text { Cronbach's } \\
\text { Alpha }\end{array}$ & $\begin{array}{c}\text { Composite } \\
\text { Reliability }\end{array}$ & AVE \\
\hline Perceived Benefit & 0.9161 & 0.9314 & 0.6298 \\
Perceived Effort & 0.8179 & 0.8689 & 0.5287 \\
Individual Factor & 0.7829 & 0.8526 & 0.5409 \\
KMS Acceptance & 0.8688 & 0.9082 & 0.669 \\
Org Factor & 0.7769 & 0.8423 & 0.5171 \\
Social Influences & 0.9777 & 0.9889 & 0.9781 \\
\hline
\end{tabular}

The composite reliability was counted to assess the internal consistency for the indicators of each construct. In contrast to Cronbach's alpha, composite reliability does not conclude that all items are just as calculated [53]. All of constructs in the research model showed great internal consistency as shown by their composite reliability scores (Table 4). Composite reliability result higher than .70 is analyzed appropriate. Composite reliability of all the constructs has more than 0.80 which showing the measurement model has high internal consistency.

\subsection{Discriminant Validity}

Discriminant validity refers to "the degree to which items differentiate among constructs or measure distinct concepts" [50-51]. To evaluate loadings, cross-loadings, and discriminant validity were compared. To show discriminant validity, loadings need to be higher than crossloadings. Simply, the indicators must give higher for their associated construct than indicators for other constructs. This recommends that the construct component rating forecasts each indicator for the linked construct much better compared to indicators for other constructs [53].

Among of test for discriminant validity in order to compare the inter-construct relationship as well as the square root of the AVE. The square root of the AVE need to higher than the inter-construct correlations [53], showing that "the constructs were correlated a lot higher with their indicators compared with other constructs in the model" [50-51]. In other words, the AVE shared between the construct and its indicators need to be greater than the variance shared between the construct to the other constructs [53].

Table 5. The Square Root of AVE

\begin{tabular}{ccccccccc}
\hline & CR & AVE & $\begin{array}{c}\text { Perceived } \\
\text { Benefit }\end{array}$ & $\begin{array}{c}\text { Perceived } \\
\text { Effort }\end{array}$ & $\begin{array}{c}\text { Ind } \\
\text { Factor }\end{array}$ & $\begin{array}{c}\text { KMS } \\
\text { Accept }\end{array}$ & $\begin{array}{c}\text { Org } \\
\text { Factor }\end{array}$ & $\begin{array}{c}\text { Social } \\
\text { Influe }\end{array}$ \\
\hline Perceived Benefit & 0.9314 & 0.6298 & 0.793 & & & & & \\
Perceived Effort & 0.8689 & 0.5287 & 0.3444 & 0.727 & & & & \\
Individual Factor & 0.8526 & 0.5409 & 0.3719 & 0.385 & 0.735 & & & \\
KMS Acceptance & 0.9082 & 0.669 & 0.5396 & 0.2892 & 0.4105 & 0.817 & & \\
Org Factor & 0.8423 & 0.5171 & 0.2385 & 0.4397 & 0.4899 & 0.2989 & 0.719 & 0.988 \\
Social Influences & 0.9889 & 0.9781 & 0.3144 & 0.2474 & 0.235 & 0.2173 & 0.122 & 0 \\
\hline
\end{tabular}

As presented in Table 5 the square root of the AVE calculation for all constructs (in diagonals) is higher than the inter-construct correlations (off-diagonals). These outcomes show that all the constructs fulfill the standards for enough discriminant validity. The conclusion, all the constructs show enough validity and reliability, showing that the measurement model is acceptable.

\subsection{Global fit Measure}

Since specified with Tenenhaus et al. (2004), a global fit measure (GoF) for PLS path modeling is the geometric method of the average communality as well as average R2 for the endogenous constructs. To maintain the validity of the PLS model, GoF value was approximated depending on the standards set up by Wetzels et al. (2009). In our research, the achieved GoF value was 0.26 . The evaluation was prepared with the baseline values of GoF 
(small=0.1, medium $=0.25$, large $=0.36$ ) because it was recommended by Wetzels et al. (2009) giving proof of appropriate of universal PLS model validity [54].

\subsection{Predictive Relevance of Model}

When mentioned previously, the size of the R2 for the endogenous variables has a predictive power indicator of the model. In order to validate the anticipating significance of the model, the sample reuse method was used as recommended by Stone (1974) and also Geisser (1975). Actually, the sample's reuse method that was said by Wold (1982) to accommodate effectively the PLS modeling method (Götz, Liehr-Gobbers, \& Krafft, 2011). Furthermore, especially, we then analyzed the predictive validity of the model by using the procedures recommended by Stone-Geisser non-parametric test [53, 55]. In order to accomplish this objective, the blindfolding procedures integrated into Smart-PLS bundle were utilized. Blindfolding procedures is created to eliminate some information and after that approximate them as missing values. Based upon that, the blindfolding procedure generates basic crossvalidating metrics Q2.

According to this method, there are distinct forms of Q2 that can be measured based upon the form of preferred forecast. A cross-validated communality Q2 could be acquired when the information factors predicted based on the latent variable scores. From different view point, when the data points are got by the LVs that predict the block concerned, a cross-validated redundancy Q2 is the outcome. The cross-validated redundancy method could be a trusted measure of the predictive relevance of the model examined [55]. If the evaluation of requirement, repetitive communality was discovered to be higher than 0 for all the endogenous variables, the model is regarded to have predictive validity, typically, the predictive relevance of the model could not be deduced [55]. The outcomes of our model show that the cross-validated redundancy for "Perceived Benefit". Perceived Effort" and "KMS Acceptance" was respectively $0.11,0.10$ and 0.19 is higher than zero. Therefore the used model predictive validity was built.

\subsection{Testing Research Model}

The hypotheses are checked by analyzing the statistical relevance of the path coefficients with t-statistics determined to make use of the bootstrap resampling method of 500 samples. The bootstrap is a "nonparametric method for approximating the accuracy of the PLS valuations" [53]. The test of the structural model includes estimates of the path coefficients indicating the strength of the relationships between the dependent independent variables; and estimates of the $\mathrm{R} 2$ values, which work with the amount of variance in the dependent variable clarified by the independent variables. We utilized the repetitive indicator method to approximate the second-order molar construct, commitment [56]. Under the repeated indicator approach, the higher-order constructs are straight determined by manifest indicators for the first-order constructs. The repetitive indicators approach enables inspection of the relative path weights of the factors creating the higher-order constructs [56]. To examine the specific hypotheses (summarized in Table 6) suggested in the research model, we evaluated the t-statistics for the consistent path coefficients by using bootstrap with 500 re-samples. We used two-tailed as well as one tailed t-test due to the fact that the hypotheses were unidirectional and also directional. The outcomes of the evaluation are illustrated in Figure 3 and recapped in Table 6.

As shown in Figure 3, the model accounts for $30 \%$ of the variance in KMS Acceptance, $18 \%$ of the variance in users' perceived benefit of using KMS, and $23 \%$ of the variance in perceived effort. Every hypothesis were bolstered not include for $\mathrm{H} 4, \mathrm{H} 7$, and $\mathrm{H} 8$. 
Table 6. Hypotheses Testing

\begin{tabular}{|c|c|c|c|c|c|}
\hline & Hypotheses & $\begin{array}{l}\text { Path } \\
\text { Coe }\end{array}$ & T-stat & P-value & Result \\
\hline $\mathrm{H} 1$ & $\begin{array}{l}\text { Individual Factor will have direct impact to } \\
\text { Perceived Benefit of using KMS }\end{array}$ & 0.28 & 3.291 & 0.0011 & Supported \\
\hline $\mathrm{H} 2$ & $\begin{array}{l}\text { Individual Factor will have direct impact to } \\
\text { Perceived Effort of using KMS }\end{array}$ & 0.22 & 4.9716 & 0.0001 & Supported \\
\hline $\mathrm{H} 3$ & $\begin{array}{l}\text { Organizational Factors will have direct } \\
\text { impact to Perceived Effort of using KMS }\end{array}$ & 0.33 & 2.1152 & 0.0352 & Supported \\
\hline $\mathrm{H} 4$ & $\begin{array}{l}\text { Organizational Factors will have direct } \\
\text { impact to Perceived Benefit of using KMS }\end{array}$ & $\overline{-}-004$ & 1.2106 & 0.2276 & $\begin{array}{l}\text { Not } \\
\text { Supported }\end{array}$ \\
\hline H5 & $\begin{array}{l}\text { Perceived Benefit will have direct impact } \\
\text { to KMS Acceptance }\end{array}$ & 0.49 & 7.1737 & 0.0001 & Supported \\
\hline $\mathrm{H} 6$ & $\begin{array}{l}\text { Perceived Effort will have direct impact } \\
\text { on Perceived benefit of using KMS }\end{array}$ & 0.24 & 2.6044 & 0.0100 & Supported \\
\hline $\mathrm{H} 7$ & $\begin{array}{l}\text { Perceived Effort will have direct impact to } \\
\text { KMS Acceptance }\end{array}$ & 0.11 & 1.7355 & 0.0833 & $\begin{array}{l}\text { Not } \\
\text { supported }\end{array}$ \\
\hline $\mathrm{H} 8$ & $\begin{array}{l}\text { Social Influences will have direct impact } \\
\text { to KMS Acceptance }\end{array}$ & 0.04 & 2.4315 & 0.0159 & $\begin{array}{l}\text { Not } \\
\text { Supported }\end{array}$ \\
\hline
\end{tabular}

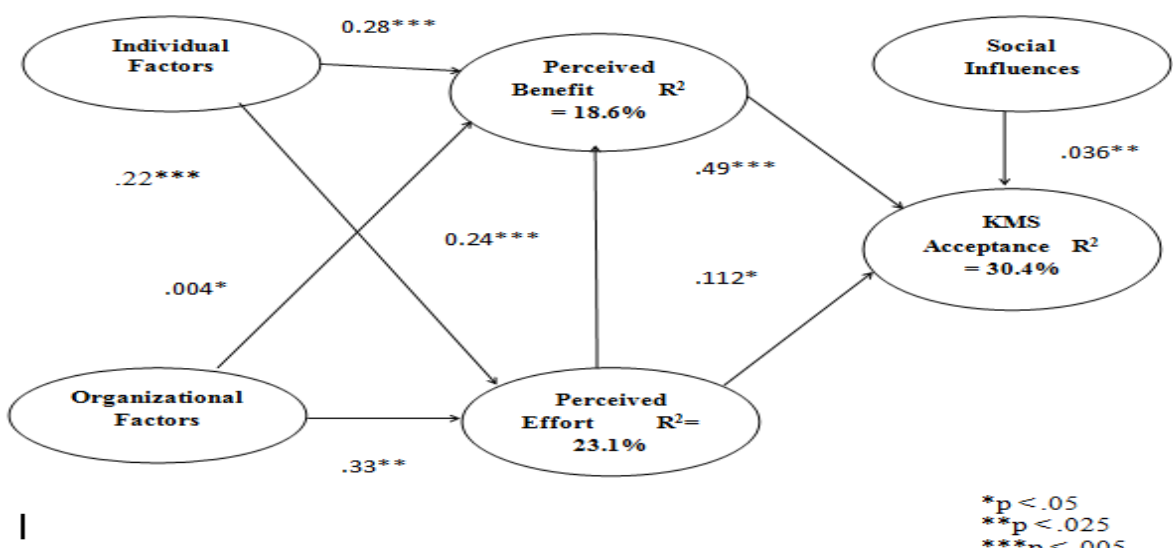

Figure 3. Path analysis result

\subsection{Discussion}

The research discovered just what affects the use of KMS in Indonesia Bank organization. We sustained the TAM (Davis, 1989) with SET to examine knowledge contributor behavior in acceptance KMS. We will talk about the findings related to each hypothesis in turn. Hypotheses 1, Consistent with Davis et al (1989) proposed, we found that individual variables can influences knowledge management system acceptance by influencing perceived benefit. This supports Davis's argument that External factor provides "the bridge between the internal beliefs, attitude, and intention represented in TAM and the various individual different situation constrains and managerially controllable intervention impinging on behavior [24]. Hypotheses 2, as hypothesized, Individual Factor will have a direct impact on perceived effort of using KMS. This finding was as we looked forward that the behavior and attitudes are conceptually comparable and strengthening. These outcomes come with those for hypothesis 1 , indicate that external factors influence perceived benefit as well as perceived effort. Furthermore, this is relevant with a study by Agarwal and Prasad (1999) found that individual different have influenced Perceived Benefit and effort in technology acceptance. Hypothesis 3, this hypothesis was supported. Our hypotheses that argue organizational Factors will have a direct impact on Perceived effort of using KMS. This relevant with previous research that found external factors for example organizational variables will influences knowledge management system acceptance by influencing perceived benefit. Hypotheses 4, we had hypothesized that Organizational Factors will have a direct impact to Perceived Benefit of using KMS. This finding has opposite to that in the literature that recommends external factors, for example, organizational variables will influences knowledge management system acceptance by influencing perceived benefit. Hypothesis 5 , this hypothesis was strongly supported. Our hypotheses that Benefit will have a 
direct impact to KMS Acceptance were strongly evident affect KMS acceptance. In the line with previous studies in KMS acceptance study aadditionally discovered that perceived usefulness is a "significance determinant" of the personal objective to use KMS and that regarded simplicity of use is a "significant secondary determinant" of use objectives [30-31], [57]. Hypotheses 6, Consistent with Davis's (1989) findings, we found that perceived effort posited to have a direct effect an indirect on behavioral intention trough perceived a benefit. Hypotheses 7 , we had hypothesized that perceived effort posited to have a direct effect behavioral intention. This finding has opposite to those in the literature that recommends a perceived effort posited to have a direct effect behavioral intention Hypothesis 8, As hypothesized, peers or superiors reflect he or she must show the behavior, weighted by the person's intention to fulfill with those others, as forecasted by the social influence model (Fulk et al. 1990), social influence utilized by the behavior and attitude of management and co-workers in a users' social and work environments can significantly affect the users' actions concerning technology use. This finding has opposite to those in the literature that recommends those social influences can be connected to fulfilment in mandatory settings which makes it have a straight effect on intention.

\section{Conclusion}

This research empirically tested how individual and organizational factors influences people behavior in accept knowledge management systems. By collecting data from 215 Indonesia Banking Institutions employees, this study found that both individual and organizational factor influences people behavior in accept KMS by affect perceived benefit variable. This study has contributed in theoretical aspect by providing detailed factors of people behavior in knowledge management systems acceptance. In a practical aspect, the results of this research can help organizations, which are currently practicing knowledge management system to develop an appropriate strategy in enhancing effective KMS implementations by considering the finding factors. The research limitation of this study is the related with sample size. In the future, parts of the model could be extracted and investigated in detail. For further intriguing upcoming research could be checking out at the differentiation among the various types of knowledge management systems adopters.

\section{References}

[1] M Ergan, T Vold, E Nilsen. Virtual Communities of Practice-Experiences from VCoP. 2014; 1: 306

[2] J Xu, M Quaddus. Examining a Model of Knowledge Management Systems Adoption and Diffusion: A Partial Least Square Approach. Knowledge-Based Systems. March 2012; 27: 18-28.

[3] R Misra, A Mukherjee, R Peterson. Value Creation in Virtual Communities: the Case of a Healthcare web site. International Journal of Pharmaceutical and Healthcare Marketing. 2008; 2: 321-337.

[4] R McDermott. Why Information Technology Inspired But Cannot Deliver Knowledge Management. California Management Review. 1999; 41: 103-117.

[5] SM Allame, BA Nouri, SY Tavakoli, SAR Shokrani. Effect of Organizational culture on Success of Knowledge Management System's Implementation (Case Study: Saderat Bank in Isfahan Province). Interdisciplinary Journal of Contemporary Research in Business. 2011; 2: 321.

[6] W Zheng, B Yang, GN McLean. Linking Organizational Culture, Structure, Strategy, and Organizational Effectiveness: Mediating Role of Knowledge Management. Journal of Business Research. 2010; 63: 763-771.

[7] C Lin, JC Wu, DC Yen. Exploring Barriers to Knowledge Flow at Different Knowledge Management Maturity Stages. Information \& Management. 2012; 49: 10-23.

[8] EF Cabrera, A Cabrera. Fostering Knowledge Sharing Through People Management Practices. The International Journal of Human Resource Management. 2005; 16: 720-735.

[9] S Assegaff, H. Mulyono. The Role of Benefit and Cost in Acceptance Knowledge Management System: Knowledge Contributor Perspectives. in The Role of Service in the Tourism \& Hospitality Industry: Proceedings of the Annual International Conference on Management and Technology in Knowledge, Service, Tourism \& Hospitality 2014 (SERVE 2014), Gran Melia, Jakarta, Indonesia, 2324 August 2014, 2015. 113.

[10] S Assegaff, K Kurniabudi, E Fernando. Impact of Extrinsic and Intrinsic Motivation Element to People Knowledge Sharing Behavior at Virtual Communities of Practices in Indonesia. Indonesian Journal of Electrical Engineering and Computer Science. 2016; 1: 619-626.

[11] MJ Donate, F Guadamillas. The Effect of Organizational Culture on Knowledge Management Practices and Innovation. Knowledge and Process Management. 2010; 17: 82-94. 
[12] $P$ Oluikpe. Developing a Corporate Knowledge Management Strategy. Journal of Knowledge Management. 2012; 16: 862-878.

[13] W David, L Fahey. Diagnosing Cultural Barriers to Knowledge Management. The Academy of Management Executive. 2000; 14: 113-127.

[14] ZM Islam, I Hasan, SU Ahmed, SM Ahmed. Organizational Culture and Knowledge Sharing: Empirical Evidence from Service Organizations. African Journal of Business Management. 2011; 5: 5900-5909.

[15] J Xu, M Quaddus. Exploring the Factors Influencing End Users' Acceptance of Knowledge Management Systems: Development of a Research Model of Adoption and Continued Use. ed: IGI Global, 2007: 57-79.

[16] M Zain, RC Rose, I Abdullah, M Masrom. The Relationship between Information Technology Acceptance and Organizational Agility in Malaysia. Information \& Management. 2005; 42; 829-839.

[17] H Hoehle, V Venkatesh. Mobile Application Usability: Conceptualization and Instrument Development. Mis Quarterly. 2015; 39; 435-472.

[18] S Kim, H Park. Effects of Various Characteristics of Social Commerce (s-commerce) on Consumers' Trust and Trust Performance. International Journal of Information Management. 2013; 33; 318-332.

[19] DH McKnight, V Choudhury, C Kacmar. Developing and Validating Trust Measures for e-Commerce: An Integrative Typology. Information Systems Research. 2002; 13: 334-359.

[20] K Siau, Z Shen. Building Customer Trust in Mobile Commerce. Communications of the ACM. April 2003; 46(4): 91-94.

[21] R Agarwal, J Prasad. Are Individual Differences Germane to the Acceptance of New Information Technologies?. Decision Sciences. 1999; 30: 361-391.

[22] TH Davenport, L Prusak. Working Knowledge: How Organizations Manage What They Know (Paperback). ed, 2000: 224.

[23] FD Davis. Perceived Usefulness, Perceived Ease of Use, and User Acceptance of Information Technology. MIS Quarterly. 1989; 13: 319-340.

[24] FD Davis, RP Bagozzi, PR Warshaw. User Acceptance of Computer Technology: A Comparison of Two Theoretical Models. Management Science. August 1, 1989 1989; 35: 982-1003.

[25] V Venkatesh, FD Davis. A Theoretical Extension of the Technology Acceptance Model: Four Longitudinal Field Studies. Management Science. 1 February 2000; 46: 186-204.

[26] V Venkatesh, MG Morris. Why Don't Men Ever Stop to Ask for Directions? Gender, Social Influence, and Their Role in Technology Acceptance and Usage Behavior. MIS Quarterly. 2000; 24: 115-139.

[27] J Xu, M Quaddus. Exploring the Factors Influencing End Users' Acceptance of Knowledge Management Systems: Development of a Research Model of Adoption and Continued Use. IGI Global. 2009: 227-248.

[28] RW Zmud. Individual Differences and MIS Success: A Review of the Empirical Literature. Management Science. 1 October 1979; 25; 966-979.

[29] P Bots. Effective Knowledge Management in Professional Organizations: Going by the Rules. 2002: $108 b-108 b$.

[30] PF Clay, AR Dennis, K Dong-Gil. Factors Affecting the Loyal Use of Knowledge Management Systems. in System Sciences, 2005. HICSS '05. Proceedings of the 38th Annual Hawaii International Conference on, 2005: 251c-251c.

[31] B Cristof, S Stefan, R Gerold. Assessing User Acceptance of a Knowledge Management System in a Global Bank: Process Analysis and Concept Development, in System Sciences, 2007. HICSS 2007. 40th Annual Hawaii International Conference on, 2007: 203c-203c.

[32] O Foloruns, SO Ogunseye. Applying an Enhanced Technology Acceptance Model to Knowledge Management in Agricultural Extension Services. Data Science Journal. 2008; 7: 31-45.

[33] M Patricia. Motivation, Incentives and Organisational Culture. Journal of Knowledge Management. 2007; 11: 28-38.

[34] C Vitari, J Moro, A Ravarini, I Bourdon. Improving KMS Acceptance: The Role of Organizational And Individuals' Influence. ed: IGI Global. 2007: 68-90.

[35] AR Dennis, BA Reinicke. Beta versus VHS and the Acceptance of Electronic Brainstorming Technology. MIS Q. 2004; 28: 1-20.

[36] F Ericsson, A Avdic. Knowledge Management Systems Acceptance. in Knowledge Management: Current Issues and Challenges, ed: IGI Global. 2003: 39-51.

[37] OK. Lee, M Wang, KH Lim, Z Peng. Knowledge Management Systems Diffusion in Chinese Enterprises: A Multistage Approach Using the Technology-Organization-Environment Framework. ed: IGI Global. 2009; 70-84.

[38] W Money, A. Turner. Assessing Knowledge Management System User Acceptance with the Technology Acceptance Model. International Journal of Knowledge Management. 2008; 1: 8-26.

[39] J Xu, M Quaddus. A Reality-based Guide to KMS Diffusion. Journal of Management Development. 2005; 24: 374-389.

[40] J Xu, M Quaddus. Exploring the Perceptions of Knowledge Management Systems. Journal of Management Development. 2005; 24; 320-334. 
[41] MF Ajzen, Understanding Attitudes and Predicting Social Behaviour EnglewoodCliffs NY Prentice Hall, Prentice-Hall, 1980.

[42] JY L Thong, CS Yap. CEO Characteristics, Organizational Characteristics and Information Technology Adoption in Small Businesses. Omega. August 1995; 23; 429-442.

[43] CL Hsu, JCC Lin. Acceptance of Blog Usage: The Roles of Technology Acceptance, Social Influence and Knowledge Sharing Motivation. Information \& Management. January 2008; 45: 65-74.

[44] D Cooper, P Schindler, Business Research Methods: McGraw-Hill Education, 2010.

[45] D Remenyi, Doing Research in Business and Management: an Introduction to Process and Method. London; Thousand Oaks, Calif.: SAGE, 1998.

[46] D Remenyi, B Williams. The Nature of Research: Qualitative or Quantitative, Narrative or Paradigmatic?. Information Systems Journal. 1996; 6: 131-146.

[47] DF Polit, CT Beck. The Content Validity Index: Are You Sure You Know What's Being Reported? Critique and Recommendations. Research in Nursing \& Health. 2006; 29: 489-497.

[48] LW Neuman, Social Research Methods, 6/E: Pearson Education, 2007.

[49] JF Hair, RE Anderson, Multivariate data analysis: Prentice Hall Higher Education, 2010.

[50] D Gefen, D Straub. A Practical Guide to Factorial Validity Using PLS-Graph: Tutorial and Annotated Example. Communications of the Association for Information Systems. 2005; 16: 109.

[51] D Gefen, DW Straub, MC Boudreau. Structural Equation Modeling and Regression: Guidelines for Research Practice. in Communications of the association for information systems, 2000.

[52] D Barclay, C Higgins, R Thompson. The Partial Least Squares (PLS) Approach to causal Modeling: Personal Computer Adoption and Use as an Illustration. Technology Studies. 1995; 2: 285-309.

[53] WW Chin. The Partial Least Squares Approach for Structural Equation Modeling. in Modern methods for Business Research, ed Mahwah, NJ, US: Lawrence Erlbaum Associates Publishers. 1998: 295336.

[54] M Wetzels, G Odekerken-Schroder, C Van Oppen. Using PLS Path Modeling for Assessing Hierarchical Construct Models: Guidelines and Empirical Illustration. Mis Quarterly. 2009; 33: 177.

[55] C Fornell, DF Larcker. Evaluating Structural Equation Models with Unobservable Variables and Measurement Error. Journal of Marketing Research. 1981; 39-50.

[56] W Chin. How to Write Up and Report PLS Analyses. in Handbook of Partial Least Squares, V. Esposito Vinzi, W. W. Chin, J. Henseler, and H. Wang, Eds., ed: Springer Berlin Heidelberg, 2010: 655-690.

[57] O Chorng-Shyong, L Jung-Yu, W Yu-Min, W Shang-Wei. An Understanding of Power Issues Influencing Employees' Acceptance of KMS: An Empirical Study of Taiwan Semiconductor Manufacturing Companies. in System Sciences, 2005. HICSS '05. Proceedings of the 38th Annual Hawaii International Conference on, 2005: 269a-269a. 